\title{
Multiomic analysis on human cell model of wolfram syndrome reveals changes in mitochondrial morphology and function
}

Agnieszka Zmyslowska1*0, Miljan Kuljanin², Beata Malachowska,4, Marcin Stanczak³, Dominika Michalek ${ }^{3}$, Aneta Wlodarczyk ${ }^{5}$, Dagmara Grot ${ }^{5}$, Joanna Taha ${ }^{6}$, Bartłomiej Pawlik,8, Magdalena Lebiedzińska-Arcisze wska ${ }^{9}$, Hanna Nieznanska ${ }^{9}$, Mariusz R. Wieckowski ${ }^{9}$, Piotr Rieske ${ }^{5}$, Joseph D. Mancias ${ }^{2}$, Maciej Borowiec ${ }^{1}$, Wojciech Mlynarski ${ }^{7 \dagger}$ and Wojciech Fendler $2,3+$

\begin{abstract}
Background: Wolfram syndrome (WFS) is a rare autosomal recessive syndrome in which diabetes mellitus and neurodegenerative disorders occur as a result of Wolframin deficiency and increased ER stress. In addition, WFS1 deficiency leads to calcium homeostasis disturbances and can change mitochondrial dynamics. The aim of this study was to evaluate protein levels and changes in gene transcription on human WFS cell model under experimental ER stress.

Methods: We performed transcriptomic and proteomic analysis on WFS human cell model_-skin fibroblasts reprogrammed into induced pluripotent stem (iPS) cells and then into neural stem cells (NSC) with subsequent ER stress induction using tunicamycin (TM). Results were cross-referenced with publicly available RNA sequencing data in hippocampi and hypothalami of mice with WFS1 deficiency.
\end{abstract}

Results: Proteomic analysis identified specific signal pathways that differ in NSC WFS cells from healthy ones. Next, detailed analysis of the proteins involved in the mitochondrial function showed the down-regulation of subunits of the respiratory chain complexes in NSC WFS cells, as well as the up-regulation of proteins involved in Krebs cycle and glycolysis when compared to the control cells. Based on pathway enrichment analysis we concluded that in samples from mice hippocampi the mitochondrial protein import machinery and OXPHOS were significantly down-regulated.

Conclusions: Our results show the functional and morphological secondary mitochondrial damage in patients with WFS.

Keywords: Wolfram syndrome, Proteomics, Transcriptomics, Mitochondria, ER stress

\footnotetext{
*Correspondence: agnieszka.zmyslowska@umed.lodz.pl

tWojciech Mlynarski and Wojciech Fendler have contributed equally to this work.

1 Department of Clinical Genetics, Medical University of Lodz, Pomorska

Str. 251, 92-213 Lodz, Poland

Full list of author information is available at the end of the article
}

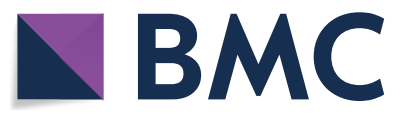

(c) The Author(s) 2021. Open Access This article is licensed under a Creative Commons Attribution 4.0 International License, which permits use, sharing, adaptation, distribution and reproduction in any medium or format, as long as you give appropriate credit to the original author(s) and the source, provide a link to the Creative Commons licence, and indicate if changes were made. The images or other third party material in this article are included in the article's Creative Commons licence, unless indicated otherwise in a credit line to the material. If material is not included in the article's Creative Commons licence and your intended use is not permitted by statutory regulation or exceeds the permitted use, you will need to obtain permission directly from the copyright holder. To view a copy of this licence, visit http://creativecommons.org/licenses/by/4.0/. The Creative Commons Public Domain Dedication waiver (http://creativeco mmons.org/publicdomain/zero/1.0/) applies to the data made available in this article, unless otherwise stated in a credit line to the data. 


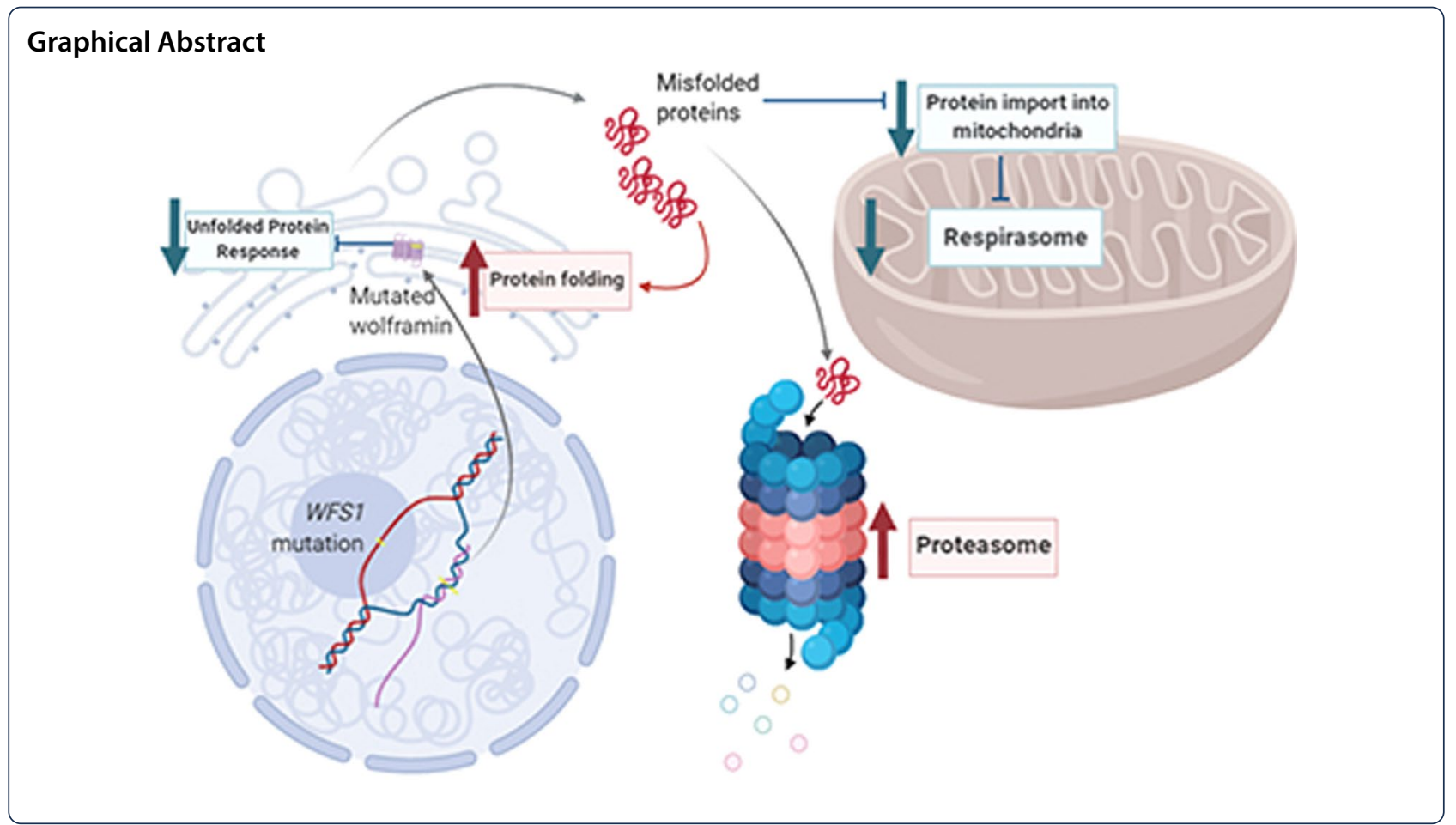

\section{Background}

Wolfram syndrome (WFS) is a rare genetic syndrome inherited in an autosomal recessive manner, which occurs as a result of the presence of pathogenic variants mainly in the WFS1 gene [1, 2]. In all patients with WFS many disorders are observed including diabetes mellitus, optic atrophy and progressive neurodegeneration, mainly involving the hippocampus, hypothalamus, cerebellum and brainstem [3]. Wolframin-the product of WFS1 gene-is an integral component of the endoplasmic reticulum (ER) and is expressed in many organs (e.g., brain, pancreas, liver, heart). This protein plays a protective role against ER stress in affected cells and its functional lack in this syndrome results in a number of biological effects and finally, a wide range of clinical symptoms observed in WFS patients $[4,5]$.

The significance of ER stress in WFS has been already described. Once the ER has exceeded its folding capacity, accumulation of unfolded protein inside the ER lumen occurs. This results in ER stress which activates the signaling pathways associated with the unfolded protein response (UPR) [6]. It is known that in the absence of Wolframin, ER stress is increased by activation of transcription of both PERK kinase (Protein kinase RNA-like ER kinase) and ATF6 factor (Activating transcription factor 6). Moreover, as a result of the stimulation by requiring inositol factor 1 (IRE1), an unconventional splicing of the mRNA encoding the X-box binding protein 1 (XBP1) is observed. Activation of all three ER stress pathways results in increase in specific ER stress markers and apoptosis of the affected cells [7-10]. Furthermore, WFS1 deficiency inducing ER stress leads to impaired cytosolic $\mathrm{Ca}^{2+}$ homeostasis and altered mitochondrial dynamics, as already suggested in an animal model of WFS and fibroblasts obtained from WFS patients $[11,12]$.

To date, no effective treatment is available for WFS patients $[13,14]$. Attempting to explain the abnormalities observed in WFS at the protein level and assessing changes in gene transcription under experimental ER stress may provide an opportunity to precisely clarify pathological mechanisms and thus exploit the potential treatment.

In the present study, proteomic and transcriptomic analyses of a human cellular model of WFS was performed.

\section{Materials and methods}

Diagnosis of WFS was confirmed in patients by direct sequencing of the WFS1 gene and/or multiplex ligationdependent probe amplification (MLPA; SALSA MLPA P163 GJB-WFS1 probemix, MRC-Holland, The Netherlands), as described previously [15]. Skin biopsies in WFS patients ( $\mathrm{n}=2$ with nonsense mutations) and healthy volunteers $(\mathrm{n}=2)$ were performed.

Next step included reprogramming process of skin fibroblasts to induced pluripotent stem (iPS) cells and 
then to trans-differentiated neural stem cells (NSC) with following induction of ER stress. This allowed us to create an experimental human cell model of WFS with enhanced ER stress effect.

\section{Cell cultures}

Fibroblasts collected from skin biopsy were transformed into iPS and NSC in cooperation with Celther Company, Poland. Next, iPS cells were cultured in Essential 8 (Life Technologies, CA, USA) on protein-coated culture vessels of the extracellular matrix (Geltrex ${ }^{\mathrm{TM}}$ LDEV-Free Reduced Growth Factor Basement Membrane Matrix Geltrex, Life Technologies, CA, USA; 1:100). After reaching the appropriate confluence, iPS cell colonies were passed using $0.5 \mathrm{mM}$ EDTA (Sigma-Aldrich, Germany) on new culture vessels and also extracellular matrix protein-coated, until the number of cells required for the analysis was reached.

The NSC were cultured in PSC Neural Induction Medium (Life Technologies, CA, USA) on proteincoated culture vessels of the extracellular matrix (Geltrex $^{\mathrm{TM}}$ LDEV-Free Reduced Growth Factor Basement Membrane Matrix Geltrex, Life Technologies, CA, US; 1:100). After reaching appropriate confluence, the cells passed using StemPro Accutase (Life Technologies, CA, USA) on new culture vessels and also extracellular matrix protein-coated, until the number of cells required for the analysis was reached. Marker analysis showed that the cells obtained were NSC and then differentiation of these cells was performed, as described previously [16].

Briefly, before differentiation, cells were checked if they had SOX-2 and nestin, but if they were OCT-4 negative. Then NSC differentiation was performed. After 7 days of differentiation, almost $25 \%$ of cells showed MAP2 expression and neuronal morphology. Neither tyrosine hydroxylase $(\mathrm{TH})$ cells nor GFAP cells were detected within these cells. Culture of NSCs for 14 days in differentiation medium did not result in any GFAP-positive cells, while single cells expressing $\mathrm{TH}$ were observed. Furthermore, the cells significantly changed their morphology and most of them, with long axons and dendrites, started to form clusters arranged in dense networks. After four weeks of differentiation, about $20 \%$ of cells became GFAP positive and astrocytic in morphology.

\section{ER stress induction}

The cells were treated with ER stress inductor tunicamycin (TM, Sigma-Aldrich, Germany; $5 \mu \mathrm{g} / \mathrm{ml}$ ) dissolved in DMSO (Sigma-Aldrich, Germany). The cells were incubated with TM and under control conditions (culture medium). After $8 \mathrm{~h}$ of incubation, the medium was collected from both culture vessels and centrifuged $(200 \times g$, $2 \mathrm{~min})$. After removing the supernatant, the remaining cells were rinsed with PBS solution and then peeled off from the vessel surface. The cells were centrifuged $(200 \times g, 5 \mathrm{~min})$ and counted and then aliquoted for further analyses.

\section{Proteomic analysis}

The NSC were then prepared for proteomic analysis, i.e. dry pellet of 10 million cells. For this purpose, an appropriate number of cells were washed twice with cold buffered saline solution without ions (PBS w/o Ca ${ }^{2+}, \mathrm{Mg}^{2+}$; vWR, PA, USA), inundated with a volume of cold PBS appropriate for the surface of the culture vessel, scraped and centrifuged $\left(330 \times g, 5 \mathrm{~min}, 4{ }^{\circ} \mathrm{C}\right)$. After supernatant removal, the cells were quickly frozen in liquid nitrogen and then stored at $-80^{\circ} \mathrm{C}$. The whole procedure was performed on ice.

\section{Proteomics-materials}

Isobaric TMT reagents and the BCA protein concentration assay kit were from ThermoFisher Scientific (Rockford, IL, USA). Empore-C18 material for in-house made Stage Tips was from 3 M (Saint Paul, MN, USA). Sep-Pak cartridges (100 mg size) were purchased from Waters (Milford, MA, USA). All solvents used for Liquid chromatography (LC) were purchased from J.T. Baker (Central Valley, PA, USA). Mass spectrometry (MS)grade trypsin and Lys-C protease were purchased from ThermoFisher Scientific and Wako (Boston, MA, USA), respectively. Complete protease inhibitors were from Millipore Sigma (Saint Louis, MO, USA). Unless otherwise noted, all other chemicals were purchased from ThermoFisher Scientific.

\section{MS sample processing}

All proteomic analyses for each patient and control samples were performed in triplicates. Cell pellets were lysed using $8 \mathrm{M}$ urea, $200 \mathrm{mM}$ 4-(2-hydroxyethyl)-1-piperazinepropanesulfonic acid (EPPS) at $\mathrm{pH} 8.5$ with protease inhibitors (one tablet per $10 \mathrm{~mL}$ of lysis buffer. Samples were further homogenized and DNA was sheared via sonication using a probe sonicator $(20 \times 0.5 \mathrm{~s}$ pulses; level 3 ). Total protein was determined using a BCA assay and proteins were stored at $-80{ }^{\circ} \mathrm{C}$ until future use. A total of $25 \mu \mathrm{g}$ of protein was aliquoted for each condition and TMT channel for further downstream processing. Protein extracts were reduced using $5 \mathrm{mM}$ tris-(2-carboxyethyl) phosphine (TCEP) for $15 \mathrm{~min}$ at room temperature. Next, samples were alkylated with $10 \mathrm{mM}$ iodoacetamide for $30 \mathrm{~min}$ in the dark at room temperature. To facilitate the removal of incompatible reagents, proteins were precipitated using chloroform and methanol. Briefly, to 100 $\mu \mathrm{L}$ of each sample, $400 \mu \mathrm{L}$ of methanol was added, followed by $100 \mu \mathrm{L}$ of chloroform with thorough vortexing. 
Next, $300 \mu \mathrm{L}$ of HPLC grade water was added and samples were vortexed thoroughly. Each sample was centrifuged at $14,000 \times g$ for $5 \mathrm{~min}$ at room temperature. The upper aqueous layer was removed and the protein pellet was washed twice with methanol and centrifuged at $14,000 \times g$ for $5 \mathrm{~min}$ at room temperature. Protein pellets were re-solubilized in $200 \mathrm{mM}$ EPPS buffer and digested overnight with Lys-C (1:100, enzyme:protein ratio) at room temperature. The next day, trypsin (1:100 ratio) was added and incubated at $37^{\circ} \mathrm{C}$ for an additional $6 \mathrm{~h}$ in a ThermoMixer set to 1000 RPM.

\section{TMT labeling}

To each digested sample, $30 \%$ anhydrous acetonitrile was added and $25 \mu \mathrm{g}$ of peptides were labeled using $\sim 55 \mu \mathrm{g}$ of TMTPro reagents (TMT1-TMT16) for $1 \mathrm{~h}$ at room temperature with constant agitation. Following labeling, $5 \%$ hydroxylamine was added to quench excess TMT reagent. To equalize protein loading a ratio check was performed by pooling $\sim 2 \mu$ of each TMT-labeled sample. Samples were pooled and desalted using an in-house packed C18 Stage Tip and analyzed by liquid chromatography (LC) tandem mass spectrometry (MS/MS). Normalization factors derived from the ratio check were used to pool samples 1:1 across all TMT channels and the combined sample was desalted using a $100 \mathrm{mg}$ Sep-Pak solid phase extraction cartridge. Eluted peptides were further fractionated using basic-pH reversed-phase (bRP) on an Agilent 300 extend C18 column and were collected into a 96 deep-well plate. Samples were consolidated into 24 fractions as previously described, and 12 nonadjacent fractions were desalted using Stage Tips prior to analyses using LC-MS/MS [17-19].

\section{Mass spectrometry and data acquisition}

All mass spectrometry data were acquired using an Orbitrap Fusion Lumos mass spectrometer in-line with a Proxeon nanoLC-1200 Ultra performance LC (UPLC) system. TMT labeled peptides were separated using an in-house packed $100 \mu \mathrm{m}$ capillary column with $35 \mathrm{~cm}$ of Accucore 150 resin $(2.6 \mu \mathrm{m}, 150 \AA$ ) (ThermoFisher Scientific) using either a $120 \mathrm{~min}$ LC gradient from 4 to $24 \%$ acetonitrile in $0.125 \%$ formic acid per run. Eluted peptides were acquired using synchronous precursor selection (SPS-MS3) method for TMT quantification. Briefly, MS1 spectra were acquired at $120 \mathrm{~K}$ resolving power with a maximum of $50 \mathrm{~ms}$ ion injection in the Orbitrap. MS2 spectra were acquired by selecting the top 10 most abundant features via collisional induced dissociation (CID) in the ion trap using an automatic gain control (AGC) of $15 \mathrm{~K}$, quadrupole isolation width of $0.5 \mathrm{~m} / \mathrm{z}$ and a maximum ion time of $50 \mathrm{~ms}$. These spectra were passed in real time to the external computer for database searching. Intelligent data acquisition (IDA) using real-time searching (RTS) was performed using Orbiter as previously described [20,21]. Peptide spectral matches were analyzed using the Comet search algorithm designed for spectral acquisition speed [22, 23]. Real-time access to spectral data was enabled by the ThermoFisher Scientific Fusion API. Briefly, peptides were filtered using simple filters that included the following: not a match to a reversed sequence, maximum PPM error 50 , minimum XCorr of 0.5 , minimum deltaCorr of 0.10 and minimum peptide length of 7 . If peptide spectra matched to above criteria, an SPS-MS3 scan was performed using up to 10 $b$ - and y-type fragment ions as precursors with an AGC of $200 \mathrm{~K}$ for a maximum of $200 \mathrm{~ms}$ with a normalized collision energy setting of 45 .

\section{Mass spectrometry data analysis}

All acquired data were searched using the open-source Comet algorithm using a previously described informatics pipeline [24-26]. We acknowledge Dr. Steven Gygi for use of a custom CORE data analysis software as part of the pipeline. Briefly, peptide spectral libraries were first filtered to a peptide false discovery rate (FDR) of less than $1 \%$ using linear discriminant analysis employing a target-decoy strategy. Spectral searches were done using a custom fasta formatted database which included common contaminants, reversed sequences with the following parameters: 50 PPM precursor tolerance, fully tryptic peptides, fragment ion tolerance of $0.9 \mathrm{Da}$ and a static modification by TMT $(+304.2071 \mathrm{Da})$ on lysine and peptide $\mathrm{N}$ termini. Carbamidomethylation of cysteine residues $(+57.021 \mathrm{Da})$ was set as a static modification while oxidation of methionine residues $(+15.995 \mathrm{Da})$ was set as a variable modification. Resulting peptides were further filtered to obtain a $1 \%$ protein FDR and proteins were collapsed into groups. Reporter ion intensities were adjusted to correct for impurities during synthesis of different TMT reagents according to the manufacturers' specifications. Lastly, protein quantitative values were column normalized so that the sum of the signal for all protein in each channel was equal to account for sample loading differences and a total sum signal-to-noise of all report ion ions of 100 was required for analysis.

\section{RNA isolation and microarrays gene expression study- transcriptomics analysis}

Dry pellets containing 1 million iPS cells each were suspended in $200 \mu \mathrm{l}$ of RNA-Later Solution (Life Technologies, Carlsbad, CA, USA) for microarray expression analysis. Cells were stored at $-80{ }^{\circ} \mathrm{C}$. Total RNA was extracted by using the RNeasy Mini Kit (Qiagen, Hilden, Germany), according to the manufacturer's protocol. The 
contamination of DNA was removed by DNA digestion using RNase-Free DNase Set (Qiagen, Hilden, Germany). RNA concentration was determined by spectrophotometrical measurement using NanoDrop 8000 Spectrophotometer (Life Technologies, Carlsbad, CA, USA). The quality of extracted RNA samples was assessed with Agilent 2200 TapeStation Bioanalyzer (Agilent Technologies, Santa Clara, CA, USA) using RNA Screen Tape Kits or High Sensitivity RNA Screen Tape Kits (Agilent Technologies, Santa Clara, CA, USA). Samples were stored at $-80{ }^{\circ} \mathrm{C}$ and selected for further analysis if they had a RNA Integrity Number (RIN) $>8$.

Next, a next generation transcriptome-wide gene-level expression profiling was performed using Clariom $^{\mathrm{TM}} \mathrm{S}$ Assay (Applied Biosystems, Thermo Fisher Scientific, MA, US). In this study, the Affymetric GeneChip ${ }^{\circledR}$ System 3000Dx v.2 platform (Thermo Fisher Scientific, MA, US) consisting of GeneChip ${ }^{\circledR}$ Hybridization Oven, GeneChip ${ }^{\circledR}$ Fluidics Station 450Dx and GeneChip ${ }^{\circledR}$ Scanner 3000Dx with AutoLoader was used.

\section{Assessment of mitochondrial metabolic activity}

In order to validate the results obtained from the proteomic analysis an additional assessment of mitochondrial respiratory chain activity in NSC WFS cells and NSC control cells has been evaluated with the use of Resazurin, as described previously [27]. An aqueous stock solution of Resazurin (Sigma R7017) with a final concentration of $0.5 \mathrm{mM}(500 \mu \mathrm{M})$ was used. After the removal of the culture medium, the cells were rinsed twice with PBS containing $\mathrm{Ca}^{2+}$ and $\mathrm{Mg}^{2+}$ ions. Next, $0.5 \mathrm{ml}$ of PBS $\left(\mathrm{Ca}^{2+} / \mathrm{Mg}^{2+}\right)$ containing $5 \mathrm{mM}$ glucose and $0.5 \mathrm{mM}$ Resazurin was added to each well of the 24-well plate where the desired cells number was previously seeded. Fluorescence measurement was carried out using the Infinite M200Pro reader (Tecan Trading AG, Switzerland) with the Magellan operating software.

\section{Quantification of protein level by sulforhodamine B (SRB) assay}

The protein concentration in each well was determined after the measurements of mitochondrial metabolic activity to standardize this parameter to the protein level in each well of the multi well plate using an SRB assay [28]. After the measurements of mitochondrial metabolic activity, cells were fixed in $1 \%$ acetic acid in ice-cold methanol for at least $24 \mathrm{~h}$ and the standard SRB procedure was followed. Colorimetric SRB measurement was performed using Infinite M200 plate reader (Tecan Trading AG, Switzerland) with the $595 \mathrm{~nm}$ wavelength.
Evaluation of mitochondrial morphology-transmission electron microscopy (TEM)

In order to perform morphological analysis of mitochondria in NSC WFS cells and control cells, transmission electron microscopy (TEM) was used. Cells were fixed by $2.5 \%$ glutaraldehyde and $2 \%$ paraformaldehyde (Electron Microscopy Sciences, PA, USA) solution for $1 \mathrm{~h}$ in $4{ }^{\circ} \mathrm{C}$. After washing three times for $10 \mathrm{~min}$ in $0.1 \mathrm{M}$ cacodylate buffer (BDH Chemicals, VWR, PA, USA). Cells were postfixed in $2 \%$ osmium tetroxide (Agar Scientific, Sigma-Aldrich, Germany) for $1 \mathrm{~h}$ at room temperature and rinsed three times for $10 \mathrm{~min}$ in deionized water. Dehydration was performed by incubating the sample in increasing ethanol concentrations and next in pure propylene oxide. During dehydration cells were stained with $1 \%$ uranyl acetate (Serva, Heidelberg, Germany) in $70 \%$ ethanol. Finally, cells were embedded in the mixture of propylene oxide (Electron Microscopy Sciences, PA, USA) and Epon resin (Serva, Heidelberg, Germany) then in pure Epon resin. After polymerization in $60{ }^{\circ} \mathrm{C}$, seventy nanometer thick sections were cut using Ultramicrotome (Leica, Vienna, Austria) and collected on TEM copper grids (Ted Pella, CA, USA). Electron micrographs were obtained with Morada camera on a JEM 1400 transmission electron microscope at $80 \mathrm{kV}$ (JEOL Co., Tokio, Japan) in the Laboratory of Electron Microscopy Core Facility, Nencki Institute of Experimental Biology, Polish Academy of Sciences, Warsaw, Poland.

\section{Validation in publicly available datasets}

Dataset for the in silico hypothesis validation-RNAsequencing data from hippocampi and hypothalami of Wfs 1 -deficient mice-was obtained from the publicly accessible database-Gene Expression Omnibus (GEO) under accession number GSE102625. RNA-seq data analysis was performed using Galaxy platform (https://usega laxy.org). Reads were preprocessed with Trim Galore! (Galaxy Version 0.6.3) on default settings and mapped to the mm10 genome by using TopHat (Galaxy Version 2.1.1). The read coverage was computed with featureCounts (Galaxy Version 1.6.4+galaxy1). Finally, the expression values were normalized with TPM normalization method (Galaxy Version 0.4.0) for further analyses. Pathway enrichment analysis was performed with Gene Set Enrichment Analysis (GSEA 4.0.0) platform using REACTOME gene sets (REACTOME_MITOCHONDRIAL_PROTEIN_IMPORT and REACTOME_RESPIRATORY_ELECTRON_TRANSPORT).

\section{Statistical analysis}

Initially, Wolframin expression was compared between WFS and healthy samples, both before and after administration of tunicamycin, using two-sided unpaired 

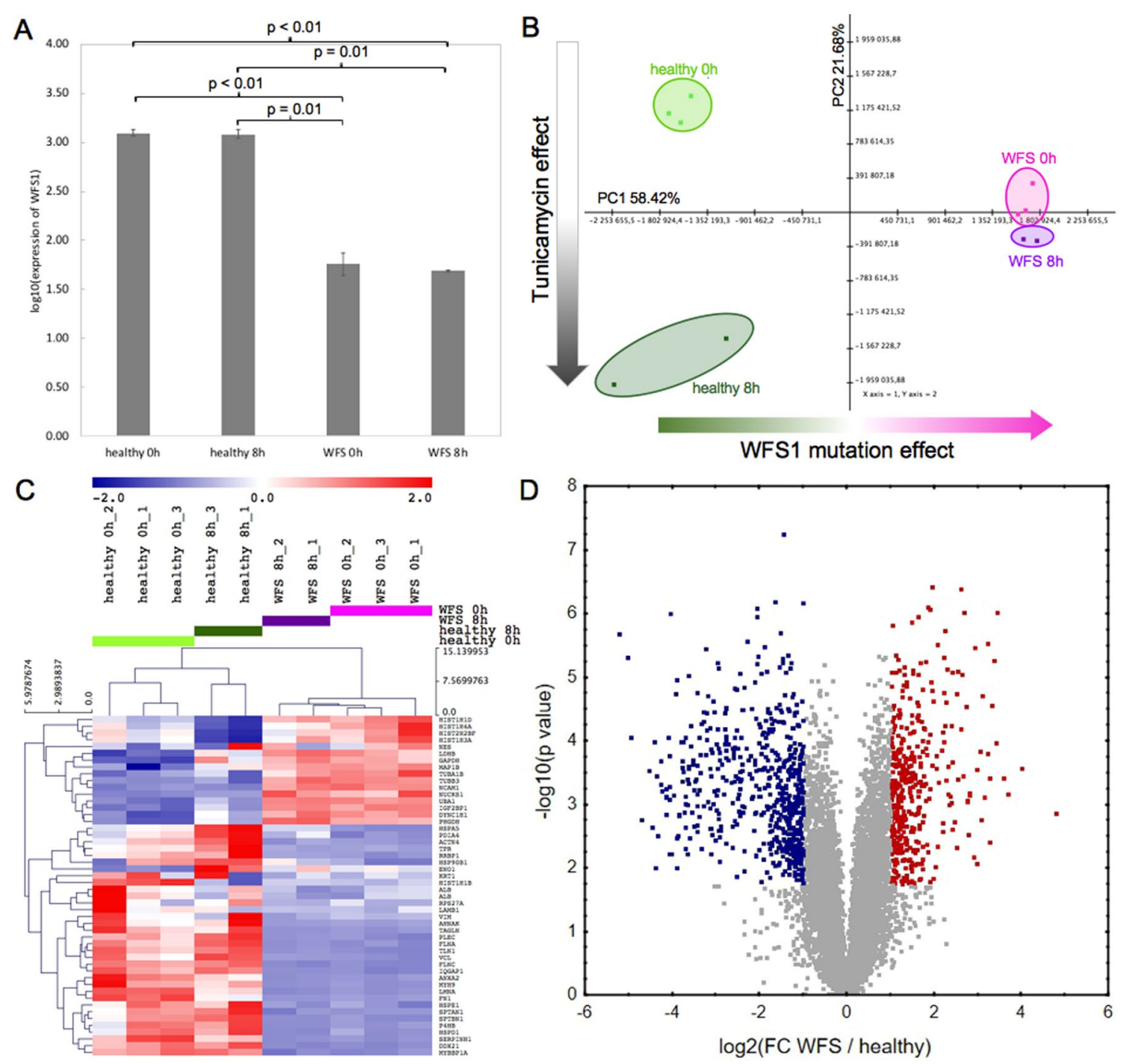

Fig. 1 Protein expression in neuronic stem cells from WFS patients and controls before and after tunicamycin administration measured by proteomics experiment. A $\log _{10}$ mean abundance of Wolframin across study groups. Whiskers represent standard deviation. One-way ANOVA $p<0.0001, p$ values of post-hoc Tukey tests are shown above corresponding groups; B Principle Component Analysis plot with annotated study groups. Arrows were added to components 1 and 2 as explanatory due to the observed effects of experimental reactions; $\mathbf{C}$ Heatmap with hierarchical clusterization performed on 50 proteins with the highest variance. Color scale represents row-standardized protein levels; D Volcano plot showing differential expression between WFS and healthy before tunicamycin administration. Significantly (FDR $<0.05)$ up-regulated (FC $>2$ ) proteins are depicted in red and down-regulated $(F D R<0.05$ and $F C<0.5)$ proteins are depicted in blue

student's t-test and Bonferroni's correction for multiple hypothesis testing.

Global differences between study groups were investigated with Principal Component Analysis (PCA) and hierarchical clustering (HCL) performed with Multiple Experiment Viewer ( $\mathrm{MeV} 4.8$ ). In two-dimensional PCA plot, groups were manually clustered and annotated. Parameters of HCL included Euclidean distance as distance measure and average linkage algorithm. Based on these analyses, outlier samples were identified and excluded.

For quantitative proteomics data analysis, fold change for each protein in every comparison was calculated and statistical significance was obtained using two-sided unpaired student's t-test, followed by Benjamini-Hochberg correction for multiple hypothesis testing (FDR). Results were visualised in using the volcano plots. 


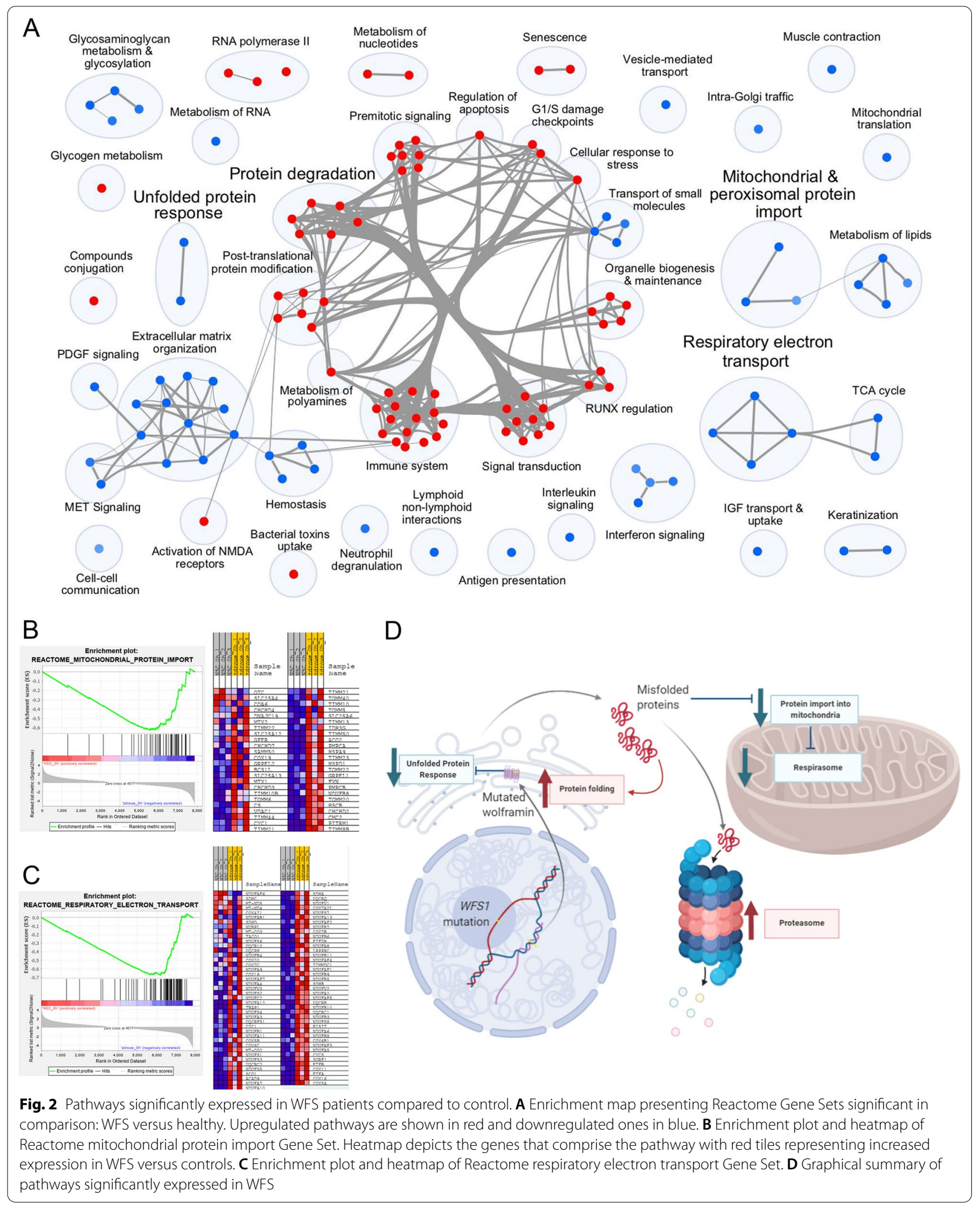


Gene Set Enrichment Analysis (GSEA) was performed for each comparison of investigated groups with Broad GSEA software (4.0.3) using Reactome 7.0 gene sets collection. Analyses were performed with 1000 permutations (gene set) and default ranking parameters.

GSEA of WFS versus Healthy comparison was visualised as enrichment map in Cytoscape 3.8.0 using the EnrichmentMap 3.3.0 plugin, with overlap coefficient 0.1 and FDR 0.05 as parameters. Network was clustered with AutoAnnotate 1.3.3, manually trimmed and annotated.
Graphical summary of pathways significantly expressed in WFS was created with BioRender.

The ANOVA Kruskal-Wallis test was used for analysis of mitochondrial morphology. Raw data along with respective statistical analysis results were presented in Additional file 1: Table S1.

\section{Results}

First, we confirmed reduced expression of Wolframin-a product of WFS1 gene-in NSC WFS cells in comparison to NSC healthy cells, both before and after the ER stress

Table 1 Summary of Reactome Gene Sets expression across comparisons in proteomics analysis

\begin{tabular}{|c|c|c|c|c|c|c|c|c|c|}
\hline \multirow{2}{*}{$\begin{array}{l}\text { Pathway } \\
\text { Reactome unfolded protein response UPR }\end{array}$} & \multicolumn{3}{|c|}{ WFS versus healthy } & \multicolumn{3}{|c|}{$\begin{array}{l}\text { WFS after tunicamycin } \\
\text { versus WFS before }\end{array}$} & \multicolumn{3}{|c|}{$\begin{array}{l}\text { Healthy after } \\
\text { tunicamycin versus } \\
\text { healthy before }\end{array}$} \\
\hline & $\downarrow$ & -1.97 & 0.001 & $\uparrow$ & 2.04 & 0.032 & $\uparrow$ & 1.46 & 0.083 \\
\hline Reactome protein folding & $\uparrow$ & 2.09 & 0.004 & $\downarrow$ & -0.81 & 0.959 & $\uparrow$ & 1.41 & 0.106 \\
\hline Reactome degradation of Gli1 by the proteasome & $\uparrow$ & 2.06 & 0.003 & $\uparrow$ & 1.22 & 0.372 & $\uparrow$ & 3.19 & $<0.001$ \\
\hline Reactome mitochondrial protein import & $\downarrow$ & -2.18 & $<0.001$ & $\downarrow$ & -1.19 & 0.496 & $\downarrow$ & -2.18 & $<0.001$ \\
\hline Reactome respiratory electron transport & $\downarrow$ & -2.59 & $<0.001$ & $\downarrow$ & -1.63 & 0.064 & $\downarrow$ & -2.64 & $<0.001$ \\
\hline
\end{tabular}

WFS, Wolfram syndrome; UPR, unfolded protein response

Table 2 Summary of transcript-level Gene Set Enrichment Analysis across comparisons in transcriptomics analysis

\begin{tabular}{|c|c|c|c|c|c|c|c|c|c|}
\hline \multirow{2}{*}{$\begin{array}{l}\text { Pathway } \\
\text { Reactome unfolded protein response UPR }\end{array}$} & \multicolumn{3}{|c|}{ WFS versus healthy } & \multicolumn{3}{|c|}{$\begin{array}{l}\text { WFS after tunicamycin } \\
\text { versus WFS before }\end{array}$} & \multicolumn{3}{|c|}{$\begin{array}{l}\text { Healthy after tunicamycin } \\
\text { versus healthy before }\end{array}$} \\
\hline & $\downarrow$ & -1.29 & 0.309 & $\uparrow$ & 2.25 & 0.001 & $\uparrow$ & 1.59 & 0.125 \\
\hline Reactome protein folding & $\downarrow$ & -1.49 & 0.156 & $\downarrow$ & -1.00 & 0.751 & $\downarrow$ & -1.77 & 0.034 \\
\hline Reactome degradation of Gli1 by the proteasome & $\downarrow$ & -1.65 & 0.092 & $\downarrow$ & -1.68 & 0.206 & $\downarrow$ & -1.81 & 0.029 \\
\hline Reactome mitochondrial protein import & $\downarrow$ & -1.25 & 0.334 & $\downarrow$ & -1.09 & 0.750 & $\downarrow$ & -1.11 & 0.463 \\
\hline Reactome respiratory electron transport & $\downarrow$ & -1.98 & 0.022 & $\downarrow$ & -1.63 & 0.201 & $\downarrow$ & -2.30 & $<0.001$ \\
\hline
\end{tabular}
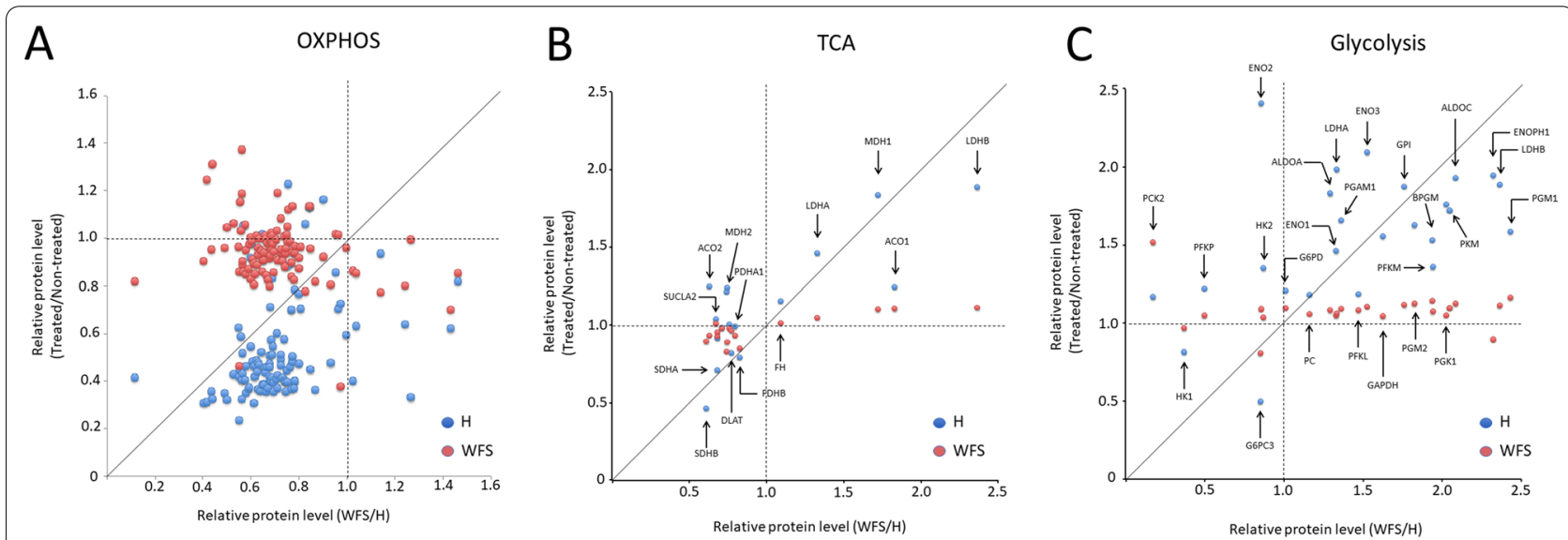

Fig. 3 Relative protein level for the individual mitochondrial function elements. WFS samples are shown in red, healthy control $(H)$ in blue. A OXPHOS Total, B TCA, C Glycolysis 

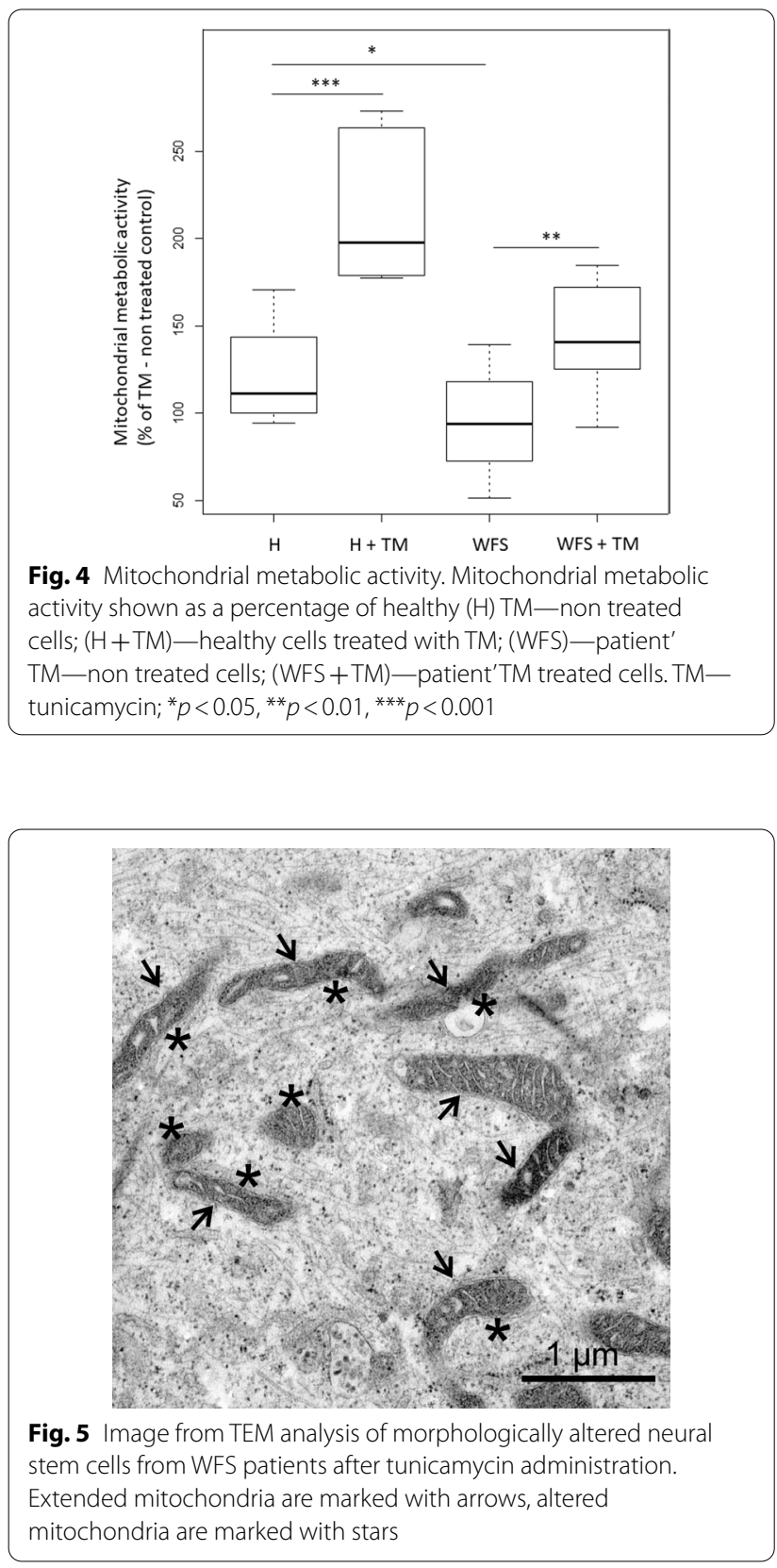

induction (Fig. 1A). After removing one outlier sample (Fig. 1B), a comprehensive proteomic analysis also indicated clusters of specific proteins in NSC cells from WFS patients compared to controls (Fig. 1C). The up- and down-regulated proteins from the study group were presented on volcano plots in reference to the control group before TM administration (Fig. 1D) and other control groups (see Additional file 2: Figure S1).

Next, specific signal pathways were identified which distinguished NSC WFS cells from healthy ones in proteomic analysis. An enrichment map has been created to show important gene sets relevant for the comparison of WFS to control (Fig. 2A) with particular focus on the Reactome mitochondrial protein import Gene Set (Fig. 2B) and Reactome respiratory electron transport Gene Set (Fig. 2C).

In normal conditions (without induced ER stress), NSC WFS cells showed significantly lower expression of proteins associated with UPR in relation to control $(\mathrm{FDR}=0.001)$. However, the TM administration significantly increased the expression of UPR-related proteins in NSC WFS (FDR =0.032) (Table 1), which also corresponded to the results of transcriptomic analysis in the WFS cells $(F D R=0.001)$ (Table 2$)$. Furthermore, in normal conditions WFS NSC cells had significantly higher expression of proteins associated with protein folding in relation to healthy cells $(F D R=0.004)$ without the significant impact of the TM addition (Table 1). Then, activation of proteasome for protein Gli1 degradation was also observed in proteomic analysis in NSC WFS in relation to controls $(F D R=0.003)$ and in control cells after TM administration (FDR $<0.001)$ (Table 1$)$, which in this case was also associated with increased transcription of proteasomal genes $(\mathrm{FDR}=0.029)$ (Table 2).

Interestingly, in normal conditions (without induced ER stress), NSC WFS cells had significantly lower expression of proteins associated with mitochondrial protein import in relation to control cells $(\mathrm{FDR}<0.001)$ and in healthy cells after TM supply $($ FDR $<0.001)$ (Table 1). Finally, this was also associated with a reduction in the respiratory electron transport in NSC WFS cells compared to control $(\mathrm{FDR}<0.001)$ and in healthy NSC cells after TM $(F D R<0.001)$ observed both in proteomic analysis (Table 1 ) and transcriptional analysis (Table 2) $(\mathrm{FDR}=0.022$ and $<0.001$, respectively).

A graphical summary of described pathways in WFS patients after the induction of ER stress due to Wolframin deficiency is presented in Fig. 2D.

Moreover, a detailed analysis of the proteins involved in OXPHOS (oxidative phosphorylation) indicated the down-regulation of subunits respiratory chain complexes in NSC WFS cells in comparison to the control cells (Fig. 3A). The level of subunits for individual respiratory chain complexes (complexes I, II, III, IV and V) is shown in Additional file 3: Figure S2. Such alterations are accompanied by up-regulation of both the Krebs cycle (tricarboxylic acid cycle-TCA) and glycolysis-involved proteins in NSC WFS compared to control cells (Fig. 3CD). The effect of TM administration was not observed in NSC WFS cells, unlike in control cells. This seems to be consistent with the Resazurin assay. Resazurin is a redox reactive compound widely used as reporter agent in assays such as cell viability or metabolic activity due to its fluorometric properties and can be used to visualize 


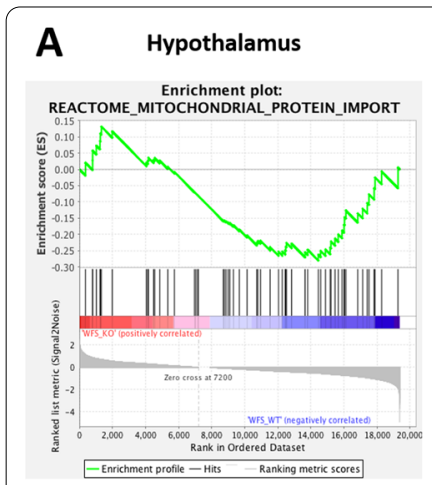

$E S=-0.28, N E S=-0.97, p=0.5269$

\section{C}

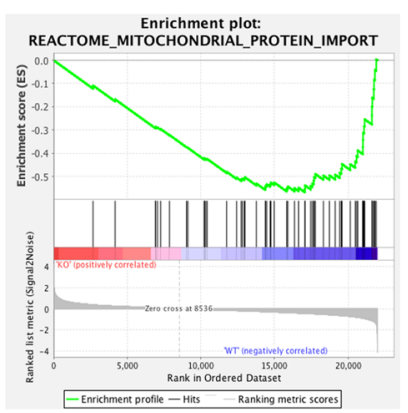

$E S=-0.57$, NES $=-2.03, p<0.0001$

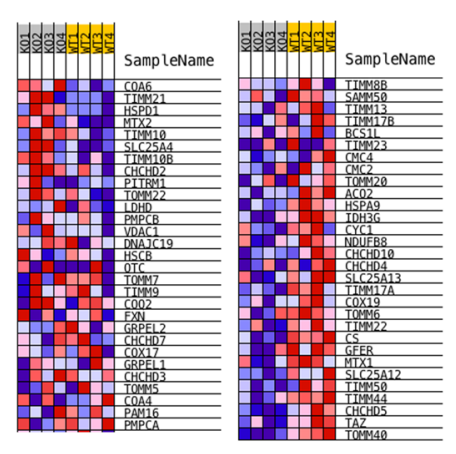

\section{B Hypothalamus}

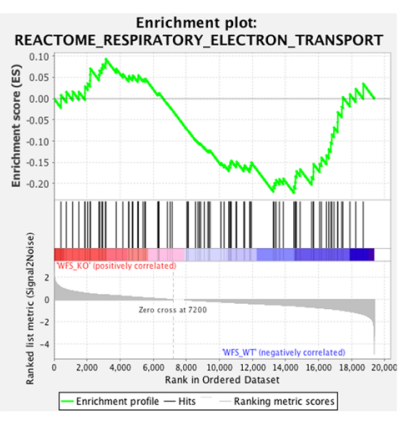

$E S=-0.22, N E S=-0.82, p=0.7827$

D Hippocampus
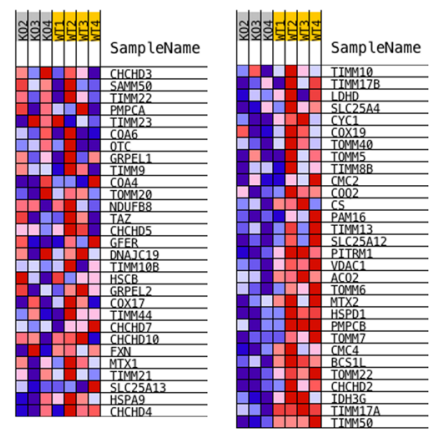

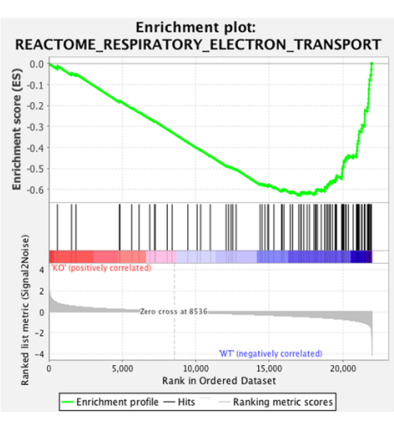

$E S=-0.63, N E S=-2.41, p<0.001$
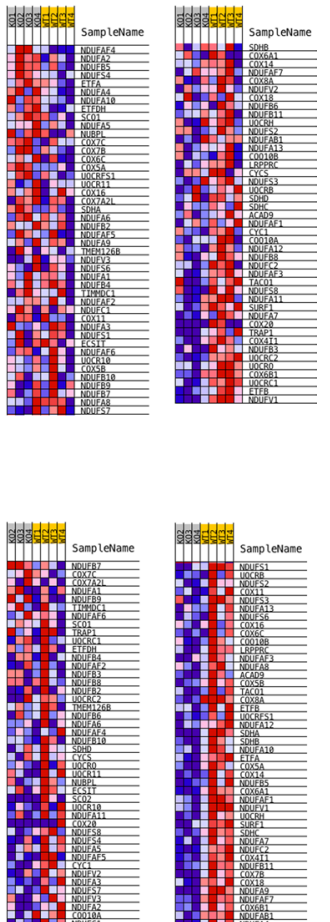

Fig. 6 Hypothesis validation on RNA-sequencing mice model data. Genes which contributed to core enrichment are marked on heatmaps with green frames. Heatmaps depict the genes that comprise the pathway with red tiles representing increased expression in WFS versus controls. A Enrichment plot and heatmap of Reactome mitochondrial protein import Gene Set performed on transcriptomics data on mice hypothalamic. B Enrichment plot and heatmap of Reactome respiratory electron transport performed on transcriptomics data on mice hypothalamic. C Enrichment plot and heatmap of Reactome mitochondrial protein import Gene Set performed on transcriptomics data on mice hippocampi. D Enrichment plot and heatmap of Reactome respiratory electron transport performed on transcriptomics data on mice hippocampi

mitochondrial activity. The mitochondrial activity in NSC control cells after TM administration was around two times higher than in TM-non treated control cells. On the other hand, TM supply to WFS NSC cells caused only $40 \%$ increase (Fig. 4). The basal mitochondrial (metabolic) activity of TM-non treated WFS NSC cells was slightly decreased in comparison to the TM-non treated NSC control cells.

The observed mitochondrial dysfunctions were accompanied by abnormalities in mitochondrial morphology in NSC WFS cells after TM administration compared to control NSC with TM, with a predominance of mitochondria with degraded mitochondrial crests (respectively: $82.0 \%$ vs. $69.2 \% ; p=0.044)$ and a tendency to a different percentage of their elongated $(60.6 \%$ vs. $64.2 \%$; $p=0.116$, respectively) and circular forms (respectively: $39.4 \%$ vs. $35.8 \%$; $p=0.116$ ) (Fig. 5).

In order to validate the presence of mitochondrial abnormalities we accessed publically-available RNAseq data (GSE102625). This dataset contained results obtained from hippocampi and hypothalami of Wfs-1 deficient mice. The samples were divided into 2 groups: wild type (WT) and homozygotes for Wfs 1 mutation $(\mathrm{KO})$ to validate in vitro experiment. Using pathway enrichment analysis we showed that that in the hypothalamus of Wfs1 $1^{\mathrm{KO} / \mathrm{WT}}$ samples showed down-regulated mitochondrial protein import and respiratory electron transport pathways (Fig. 6A-B). However, the comparisons were not significant (NES $=-0.97, p=0.5269$; $\mathrm{NES}=-0.82, p=0.7827$, respectively). In case of hippocampus however both mitochondrial protein import $(\mathrm{NES}=-2.03, \quad p<0.0001)$ and respiratory electron transport pathways were significantly down-regulated $(\mathrm{NES}=-2.41, p<0.0001) \quad($ Fig. $6 \mathrm{C}-\mathrm{D})$ in $\mathrm{Wfs} 1^{\mathrm{KO} / \mathrm{WT}}$ animals.

\section{Discussion}

For the first time, proteomic and transcriptomic analyses were performed on a human model of Wolfram syndrome based on iPS cells and NSC line from the skin fibroblasts of patients with WFS and additionally 
experimental induction of stress ER in such cell lines. This enabled a comprehensive mapping and analysis of the mechanisms occurring in WFS patients from the induction of ER stress due to Wolframin deficiency. Additionally, RNA sequences of hippocampi and hypothalami from $W f_{s} 1$-deficient mice were analyzed.

Our results confirmed a reduced expression of UPRrelated proteins and increased expression of proteins associated with protein folding in the analyzed cells in relation to control. Previous studies on pathological mechanisms of WFS highlighted the role of WFS1 as a negative regulator of the UPR-pathway and the significant contribution of hyperactive ATF6 to the activation of apoptosis-promoting genes in the course of WFS [4-6, 29].

We have also observed increased activation of proteasomes for the degradation of Gli1 protein in relation to control. Gli1 is one of the most advanced hedgehog $(\mathrm{Hh})$ signal molecules, which directly regulate the induction of various $\mathrm{Hh}$ target genes and are related to development and tissue regeneration, but also to unexpected effects such as cancer or neurodegeneration [30,31]. Thus, proteasome activation resulting in controlled degradation of proteins with lower molecular weights, including signal proteins with short half-life and abnormally folded proteins seems to be a beneficial effect. Moreover, no similarities can be found with another neurodegenerative disease such as Parkinson's disease (PD), in which the mechanism of inhibiting degradation by proteasome was previously described [32].

However, our proteomic data from NSC cells with WFS1 mutation showed the most significant decrease in both mitochondrial protein import and respiratory electron transport as compared to control cells. Also, the transcription of genes associated with the mitochondrial respiratory chain was reduced in mutated cell lines, which was consistent with the changes observed by us at the proteomic level. These results, including the analysis of particular subunits of individual respiratory chain complexes, showed severe mitochondrial dysfunction at the level of OXPHOS. In addition, the results of the analysis of RNA-sequencing data from hippocampi of $W f_{S} 1$-deficient mice confirmed a decrease in the pathway associated with mitochondrial protein import, which leads to down-regulation of OXPHOS subunits.

This seems to further support our observations made in the functional analysis of mitochondria, in the Resazurin assay, where we observed much smaller effect of TM in NSC WFS cells in comparison to the TM-treated control cells. All the results indicated the dysfunction of the respiratory chain complex with simultaneous activation of glycolytic processes visualized by the increased level of enzymes involved in this metabolic pathway. To our knowledge, only one proteomic analysis has been performed so far on an animal model of Wolfram syndrome, which included an evaluation of the muscle of Wfs 1deficient mice and showed mitochondrial disturbances. A significant increase in the concentration of mitochondrial proteins in the muscle of $\mathrm{W} f s 1$-deficient mice was noted. Compared to the wild type, the efficiency of ATP synthesis was decreased in the mitochondria of W $f_{s} 1$ deficient $\mathrm{KO}$ mice due to higher proton leak-dependent respiration, but no difference in OXPHOS-dependent respiration was found [33].

Other studies on rat primary neuronal cultures showed changes in mitochondria regarding their dynamics and selective degradation and inhibition. The authors indicated that a deficiency of the WFS1 gene could trigger an ER stress cascade that interfered with the IP3 receptor calcium channel and changed calcium homeostasis. This led to increased mitophagy and mitochondrial fusion disorders, which resulted in lower ATP levels and thus inhibited neuronal development [11]. Moreover, these results suggested that a deficiency of WFS1 might activate the PINK1 and Parkin pathway, participating in mitochondrial movement and dynamics [34, 35]. Other researchers showed that WFS1 silencing in HEK cells affected gene expression belonging to Parkinson's signaling pathway, indicating the involvement of mitochondria in neurodegenerative disorder development [36].

It is therefore known that interactions between ER stress and mitochondria are crucial for mitochondrial function, regulation of $\mathrm{Ca}^{2+}$ homeostasis and apoptosis of affected cells [37, 38]. Thus, some recent studies confirmed the presence of "mitochondria-associated ER membranes" (MAMs), a key player in many neurodegenerative diseases. Their involvement in various neurodegenerative diseases such as Alzheimer disease (AD), PD and Huntington disease (HD) has already been demonstrated [39-42]. Moreover, the participation of MAMs in relation to another subtype of Wolfram syndrome with mutations in the CISD2 gene-the WFS2 syndromewas also proved. Despite only mild changes in mitochondrial morphology, the WFS2 patient's fibroblast culture showed a defect in the respiratory chain in complexes I and II, as well as a tendency towards reduced ATP levels [43]. Further studies also indicated a potential functional role of WFS1 in MAMs [11, 40, 44, 45]. A recent study conducted by researchers on skin fibroblasts obtained from patients with WFS1 syndrome did not confirm primary mitochondrial damage or changes in their morphology. However, the authors pointed out that the $\mathrm{Ca}^{2+}$ transmission between ER and mitochondria was abnormal and this disorder occurred at the point of contact between the organelles and thus in MAMs [46]. 
To date, other authors have confirmed that WFS1 can form a complex with a neuronal calcium sensor 1 (NCS1) and inositol 1,4,5-trisphosphate receptor $\left(\mathrm{IP}_{3} \mathrm{R}\right)$ promoting $\mathrm{Ca}^{2+}$ transfer between ER and mitochondria. In addition, they noted that NCS1 is reduced in WFS1-null fibroblasts of WFS1 patients, which decreased the interaction of ER-mitochondria and $\mathrm{Ca}^{2+}$ exchange. However, no changes were found in the morphology of mitochondria in WFS1-null fibroblasts, as we observed in TEM morphometric analysis in WFS NSC mutant cells. Interestingly, the overexpression of NCS1 in that study not only restored the interaction of ER-mitochondria and $\mathrm{Ca}^{2+}$ transfer, but also saved the mitochondrial dysfunction [12].

Thus, our results on NSC cells obtained from skin fibroblasts of WFS1 patients confirm the functional and morphological secondary mitochondrial damage in the course of this disease. The limitation seems to be the use of iPS cells rather than NSC for transcriptomic analysis.

\section{Conclusions}

In summary, it seems that the ER stress in the course of Wolfram syndrome is only the beginning of disorders leading to intensification of changes in the energy center of cells which are mitochondria. This comprehensive assessment is therefore not only of a cognitive nature, but can contribute to the development of future therapeutic intervention in ER-mitochondria cross-talk in patients with Wolfram syndrome.

\begin{abstract}
Abbreviations
AD: Alzheimer disease; ATF6: Activating transcription factor 6; FDR: False discovery rate; GEO: Gene Expression Omnibus; GSEA: Gene Set Enrichment Analysis; HCL: Hierarchical clustering; Hh: Hedgehog; HD: Huntington disease; iPS: Induced pluripotent stem cells; IRE1: Requiring inositol factor 1; IDA: Intelligent data acquisition; LC: Liquid chromatography; MAMs: Mitochondria-associated ER membranes; MLPA: Multiplex ligation-dependent probe amplification; MS: Mass spectrometry; NSC: Neural stem cells; OXPHOS: Oxidative phosphorylation; PD: Parkinson disease; PCA: Principal Component Analysis; PERK: Protein kinase RNA-like ER kinase; RTS: Real-time searching; SRB: Sulforhodamine B; TCA: Tricarboxylic acid cycle; TEM: Transmission electron microscopy; TH: Tyros ine hydroxylase; UPR: Unfolded protein response; WFS: Wolfram syndrome; $\mathrm{XBP} 1$ : $\mathrm{X}$-box binding protein 1 .
\end{abstract}

\section{Supplementary Information}

The online version contains supplementary material available at https://doi. org/10.1186/s12964-021-00791-2.

Additional file 1: Table S1. List of genes and proteins generated in omics analyses for the project.

Additional file 2: Fig. S1. Global differences between study groups and pairwise differential expressions. A Principal Component Analysis with annotated study groups before exclusion of the outlier from healthy $8 \mathrm{~h} ; \mathbf{B}$ Healthy $8 \mathrm{~h}$ after tunicamycin administration vs healthy before tunicamycin delivery; CWFS 8 h after tunicamycin administration vs WFS before tunicamycin administration; D WFS before tunicamycin delivery vs healthy $8 \mathrm{~h}$ after tunicamycin administration; $\mathbf{E}$ WFS $8 \mathrm{~h}$ after tunicamycin delivery vs healthy $8 \mathrm{~h}$ after tunicamycin administration. Significantly $(F D R<0.05)$ up-regulated $(F C>2$ ) proteins are depicted in red and down-regulated ( $F C<0.5)$ proteins are depicted in blue.

Additional file 3: Fig. S2. Relative protein level for specific respiratory chain complexes. WFS samples are shown in red, healthy control $(\mathrm{H})$ in blue. $\mathbf{A ~ C l}$ of respiratory chain, $\mathbf{B}$ Cll of respiratory chain, $\mathbf{C}$ CIII of respiratory chain, D CIV of respiratory chain, E CV of respiratory chain.

\section{Acknowledgements}

We express our gratitude to patients and their families participating in the study for their contribution. We would like to thank Prof. Agnieszka Dobrzyn from the Nencki Institute of Experimental Biology, Polish Academy of Sciences, Warsaw, Poland for her invaluable advice in pointing out the direction of mitochondrial research.

\section{Authors' contributions}

A.Z. collected data and wrote the draft of the manuscript. M.K. and J.D.M. performed proteomics analysis. M.S, D.M. and B.M. performed statistical analyses. B.P. and J.T. performed RNA isolation and transcriptomics analysis. M.R.W. and M.L-A. participated in designing and conducting mitochondrial analyses. A.W., D.G and P.R. participated in analyses of cell cultures. M.B. performed genetic analyses. WM. participated in the transcriptomics assessment. H.N. performed TEM analysis. W.F. performed statistical analyses and contributed to writing the manuscript. All authors read and approved the final manuscript.

\section{Funding}

This study is supported by National Science Centre grants No 2014/15/B/ NZ5/01579 and 2015/19/B/NZ5/02243 and Diabetes Poland Scientific Grant with B.M. as its principal investigator.

\section{Availability of data and materials}

The data analyzed during the current study are available from the corresponding author on request.

\section{Declarations}

\section{Ethics approval and consent to participate}

The study protocol was approved by the University Bioethics Committee at the Medical University in Lodz, Poland (RNN/73/14/KE).

\section{Consent for publication}

Patients have written informed consent for participation in the study and publication. All procedures followed were in accordance with the ethical standards of the responsible committee on human experimentation (institutional and national) and with the Declaration of Helsinki.

\section{Competing interests}

The authors declare that they have no competing interests in relation to this work.

\section{Author details}

${ }^{1}$ Department of Clinical Genetics, Medical University of Lodz, Pomorska Str. 251, 92-213 Lodz, Poland. Department of Radiation Oncology, Dana-Farber Cancer Institute, Boston, MA, USA. ${ }^{3}$ Department of Biostatistics and Translational Medicine, Medical University of Lodz, Lodz, Poland. ${ }^{4}$ Department of Radiation Oncology, Einstein College of Medicine, Bronx, NY, USA. ${ }^{5}$ Department of Tumor Biology, Medical University of Lodz, Lodz, Poland. ${ }^{6}$ Central Laboratory for Genetic Research in Pediatric Oncology "Oncolab", Medical University of Lodz, Lodz, Poland. ${ }^{7}$ Department of Pediatrics, Oncology and Hematology, Medical University of Lodz, Lodz, Poland. ${ }^{8}$ Postgraduate School of Molecular Medicine, Medical University of Warsaw, Warsaw, Poland. ${ }^{9}$ Nencki Institute of Experimental Biology, Polish Academy of Sciences, Warsaw, Poland.

Received: 6 July 2021 Accepted: 1 October 2021

Published online: 20 November 2021 


\section{References}

1. Cano A, Rouzier C, Monnot S, Chabrol B, Conrath J, Lecomte P, French Group of Wolfram Syndrome, Vialettes B, et al. Identification of novel mutations in WFS1 and genotype-phenotype correlation in Wolfram syndrome. Am J Med Genet. 2007;143:1605.

2. Qian X, Qin L, Xing G, Cao X. Phenotype prediction of pathogenic nonsynonymous single nucleotide polymorphisms in WFS1. Sci Rep. 2015;5:14731

3. Hershey T, Lugar HM, Shimony JS, Rutlin J, Koller JM, Perantie DC, Washington University Wolfram Study Group, et al. Early brain vulnerability in Wolfram syndrome. PLoS ONE. 2012;7:e40604. https://doi.org/10.1371/ journal.pone.0040604

4. Fonseca SG, Ishigaki S, Oslowski CM, Lu S, Lipson KL, Ghosh R, et al. WFS 1 gene negatively regulates ER stress signaling in rodent and human cells. J Clin Investig. 2010;120:744.

5. Fonseca SG, Fukuma M, Lipson KL, Nguyen LX, Allen JR, Oka Y, et al. WFS1 is a novel component of the unfolded protein response and maintains homeostasis of the endoplasmic reticulum in pancreatic-cells.J Biol Chem. 2005;280:39609.

6. Pallotta MT, Tascini G, Crispoldi R, Orabona C, Mondanelli G, Grohmann $U$, et al. Wolfram syndrome, a rare neurodegenerative disease: from pathogenesis to future treatment perspectives. J Transl Med. 2019;17:238. https://doi.org/10.1186/s12967-019-1993-1.

7. Rojas-Rivera D, Rodriguez DA, Sepulveda D, Hetz C. ER stress sensing mechanism: putting off the brake on UPR transducers. Oncotarget. 2018:9:19461

8. Martınez G, Duran-Aniotz C, Cabral-Miranda F, Vivar JP, Hetz C. Endoplasmic reticulum proteostasis impairment in aging. Aging Cell. 2017;16:615.

9. Zhang SX, Sanders E, Fliesler SJ, Wang JJ. Endoplasmic reticulum stress and the unfolded protein responses in retinal degeneration. Exp Eye Res. 2014; 125:30.

10. McLaughlin T, Falkowski M, Park JW, Keegan S, Elliott M, Wang JJ, et al. Loss of XBP1 accelerates age-related decline in retinal function and neurodegeneration. Mol Neurodegener. 2018;13:16.

11. Cagalinec M, Liiv M, Hodurova Z, Hickey MA, Vaarmann A, Mandel M, et al. Role of mitochondrial dynamics in neuronal development: Mechanism for Wolfram syndrome. PLOS Biol. 2016;14:e1002511.

12. Angebault C, Fauconnier J, Patergnani S, Rieusset J, Danese A, Affortit CA et al. ER-mitochondria cross-talk is regulated by the $\mathrm{Ca}^{2+}$ sensor ncs 1 and is impaired in Wolfram syndrome. Sci Signal. 2018;11:eaaq1380. https:// doi.org/10.1126/scisignal.aaq1380.

13. Rohayem J, Ehlers C, Wiedemann B, Holl R, Oexle K, Kordonouri O, Wolfram Syndrome Diabetes Writing Group, et al. Diabetes and neurodegeneration in Wolfram syndrome: a multicenter study of phenotype and genotype. Diabetes Care. 2011;34:1503.

14. Barrett TG, Bundey SE, Macleod AF. Neurodegeneration and diabetes: UK nationwide study of Wolfram (DIDMOAD) syndrome. Lancet. 1995;346(8988):1458.

15. Zmyslowska A, Borowiec M, Antosik K, Szalecki M, Stefanski A, Iwaniszewska B, et al. Wolfram syndrome in the Polish population: novel mutations and genotype-phenotype correlation. Clin Endocrinol (Oxf). 2011;75:636.

16. Winiecka-Klimek M, Smolarz M, Walczak MP, Zieba J, Hulas-Bigoszewska K, Kmieciak B, et al. SOX2 and SOX2-MYC reprogramming process of fibroblasts to the neural stem cells compromised by senescence. PLoS ONE. 2015;10:e0141688.

17. Paulo JA. Nicotine alters the proteome of two human pancreatic duct cell lines. JOP. 2014;15:465.

18. Paulo JA, Gygi SP. Nicotine-induced protein expression profiling reveals mutually altered proteins across four human cell lines. Proteomics. 2017; 17:1600319.

19. Navarrete-Perea J, Yu Q, Gygi SP, Paulo JA. Streamlined tandem mass tag (SL-TMT) protocol: an efficient strategy for quantitative (phospho) proteome profiling using tandem mass tag-synchronous precursor selection-MS3. J Proteome Res. 2018;17:2226.

20. Erickson BK, Mintseris J, Schweppe DK, Navarrete-Perea J, Erickson AR, Nusinow DP, et al. Active instrument engagement combined with a realtime database search for improved performance of sample multiplexing workflows. J Proteome Res. 2019;18:1299.
21. Schweppe DK, Eng JK, Qing Y, Bailey D, Rad R, Navarrete-Perea J, et al. Fullfeatured, real-time database searching platform enables fast and accurate multiplexed quantitative proteomics. J Proteome Res. 2020;19:2026.

22. Eng JK, Hoopmann MR, Jahan TA, Egerton JD, Noble WS, MacCoss MJ. A deeper look into comet-implementation and features. J Am Soc Mass Spectrom. 2015;26:1865.

23. Eng JK, Jahan TA, Hoopmann MR. Comet: an open-source MS/MS sequence database search tool. Proteomics. 2013;13:22.

24. McAlister GC, Huttlin EL, Haas W, Ting L, Jedrychowski MP, Rogers JC, et al. Increasing the multiplexing capacity of TMTs using reporter ion isotopologues with isobaric masses. Anal Chem. 2012;84:7469.

25. Beausoleil SA, Villén J, Gerber SA, Rush J, Gygi SP. A probability-based approach for high-throughput protein phosphorylation analysis and site localization. Nat Biotechnol. 2006:24:1285.

26. Huttlin EL, Jedrychowski MP, Elias JE, Goswami T, Rad R, Beausoleil SA, et al. A tissue-specific atlas of mouse protein phosphorylation and expression. Cell. 2010;143:1174.

27. Abu-Amero KK, Bosley TM. Detection of mitochondrial respiratory dysfunction in circulating lymphocytes using Resazurin. Arch Pathol Lab Med. 2005:129:1295.

28. Vichai V, Kirtikara K. Sulforhodamine B colorimetric assay for cytotoxicity screening. Nat Protoc. 2006;1:1112.

29. Almanza A, Carlesso A, Chintha C, Creedican S, Doultsinos D, Leuzzi B, et al. Endoplasmic reticulum stress signalling - from basic mechanisms to clinical applications. FEBS J. 2019;286:241.

30. Matsuhisa K, Saito A, Asada R, Kanemoto S, Kaneko M, Imaizumi K. The physiological roles of ER stress transducer BBF2H7/CREB3L2 and its potential as a target of disease therapy. Med Res Arch. 2016;4:1.

31. Niewiadomski P, Niedziółka SM, Markiewicz Ł, Uśpieński T, Baran B, Chojnowska K. Gli proteins: regulation in development and cancer. Cells. 2019;8:147.

32. Bentea $E$, Verbruggen $L$, Massie A. The proteasome inhibition model of Parkinson's disease. J Parkinsons Dis. 2017;7:31.

33. Eimre M, Paju K, Peet N, Kadaja L, Tarrend M, Kasvandik S, et al. Increased mitochondrial protein levels and bioenergetics in the musculus rectus femoris of Wfs1-deficient mice. Oxid Med Cell Longev. 2018;2018:3175313.

34. Wang $X$, Schwarz TL. The mechanism of $\mathrm{Ca}^{2+}$-dependent regulation of kinesin-mediated mitochondrial motility. Cell. 2009;136:163-74.

35. Gegg ME, Cooper JM, Chau KY, Rojo M, Schapira AH, Taanman JW. Mitofusin 1 and mitofusin 2 are ubiquitinated in a PINK1/parkin-dependent manner upon induction of mitophagy. Hum Mol Genet. 2010;9:4861.

36. Kõks S, Overall RW, Ivask M, Soomets U, Guha M, Vasar E, et al. Silencing of the WFS1 gene in HEK cells induces pathways related to neurodegeneration and mitochondrial damage. Physiol Genom. 2013;45:182.

37. Grimm S. The ER-mitochondria interface: the social network of cell death Biochim Biophys Acta. 2012;1823:327.

38. Marchi S, Patergnani S, Missiroli S, Morciano G, Rimessi A, Wieckowski MR, et al. Mitochondrial and endoplasmic reticulum calcium homeostasis and cell death. Cell Calcium. 2018;69:62.

39. Jędrak P, Mozolewski P, Węgrzyn G, Więckowski MR. Mitochondrial alterations accompanied by oxidative stress conditions in skin fibroblasts of Huntington's disease patients. Metab Brain Dis. 2018;33:2005.

40. Delprat B, Maurice T, Delettre C. Wolfram syndrome: MAMs' connection? Cell Death Dis. 2018:9:364

41. Ramalingam M, Huh YJ, Lee YI. The impairments of alpha-Synuclein and mechanistic target of Rapamycin in rotenone-induced SH-SY5Y cells and mice model of Parkinson's disease. Front Neurosci. 2019:13:1028.

42. Area-Gomez E, Castillo MDCL, Tambini MD, Guardia-Laguarta C, de Groof AJC, Madra M, et al. Upregulated function of mitochondria-associated ER membranes in Alzheimer disease. EMBO J. 2012;31:4106.

43. Rouzier C, Moore D, Delorme C, Lacas-Gervais S, Ait-El-Mkadem S, Fragaki $K$, et al. A novel CISD2 mutation associated with a classical Wolfram syndrome phenotype alters $\mathrm{Ca}^{2+}$ homeostasis and ER-mitochondria interactions. Hum Mol Genet. 2017;26:1599.

44. Zatyka M, Da Silva XG, Bellomo EA, Leadbeater W, Astuti D, Smith J, et al, Sarco(endo)plasmic reticulum ATPase is a molecular partner of Wolfram syndrome 1 protein, which negatively regulates its expression. Hum Mol Genet. 2015;24:814-27.

45. Morikawa S, Tajima T, Nakamura A, Ishizu K, Ariga T. A novel heterozygous mutation of the WFS1 gene leading to constitutive endoplasmic 
reticulum stress is the cause of Wolfram syndrome. Pediatr Diabetes. 2017;18:934-41.

46. La Morgia C, Maresca A, Amore G, Gramegna LL, Carbonelli M, Scimonelli $E$, et al. Calcium mishandling in absence of primary mitochondrial dysfunction drives cellular pathology in Wolfram Syndrome. Sci Rep. 2020;10:4785

\section{Publisher's Note}

Springer Nature remains neutral with regard to jurisdictional claims in published maps and institutional affiliations.
Ready to submit your research? Choose BMC and benefit from:

- fast, convenient online submission

- thorough peer review by experienced researchers in your field

- rapid publication on acceptance

- support for research data, including large and complex data types

- gold Open Access which fosters wider collaboration and increased citations

- maximum visibility for your research: over $100 \mathrm{M}$ website views per year

At $\mathrm{BMC}$, research is always in progress.

Learn more biomedcentral.com/submissions 